\title{
A MANDRÁGORA, OU DA FENOMENLOGIA DA OPORTUNIDADE EM MAQUIAVEL
}

\section{Sergio Nunes Melo ${ }^{1,2}$}

\begin{abstract}
Resumo: Este artigo visa examinar a comédia A Mandrágora, de Maquiavel, a partir de uma leitura fenomenológica do texto teatral. $\mathrm{O}$ artigo se insere na apreciação feminista contemporânea de Maquiavel, visto que essa visão é perfeitamente compatível com a agência feminina e humana incontestavelmente representada na peça pela ação da personagem Lucrécia. Argumenta-se que a oportunidade é dramatizada como uma metáfora da circunstância decisiva, a qual deve ser confrontada com determinação a fim de tornar possível a restauração da pólis. Ressalta-se ainda uma crítica à visão cristã de mundo, bem estabelecida no Renascimento através da difusão da obra de Santo Agostinho; crítica essa que consequentemente afirma a visão inerente ao pensamento maquiaveliano de que a agência humana, exatamente por ser limitada frente à contingência, precisa transgredir a rigidez dos costumes sociais em momentos cruciais.
\end{abstract}

Palavras-chave: Agência corporal. Fortuna. Política. Maquiavel.

\section{BREVE INTRODUÇÃO A MAQUIAVEL E SUA RESSONÂNCIA HOJE}

Mais de quatro séculos separam a contemporaneidade da morte de Niccolò Machiavelli - ou Maquiavel, doravante, conforme a grafia vernácula. Hoje, a tendência é de que o senso comum perceba o campo semântico que compreende os termos 'maquiavélico' e 'maquiavelismo' como inescapavelmente ligado à manipulação perversa e calculista seja da sociedade ou de um indivíduo em nome da aquisição e da manutenção do poder. A máxima "os fins justificam os meios", frequentemente citada como quintessência do discurso maquiaveliano, não é da autoria de Maquiavel, o que demonstra que, muitas vezes, aquilo que se pensa ser conhecimento não é mais do que uma noção superficial bem difundida. Já no âmbito da pesquisa

1 Professor Adjunto do Curso de Artes Cênicas da UFSC. E-mail: sergio.nmelo@gmail.com

2 Este artigo é uma elaboração a posteriori de uma comunicação proferida em uma mesa redonda sobre política e literatura à qual fui convidado para falar sobre A Mandrágora. 
acadêmica, ao contrário, se levarmos em conta a profusão de publicações a partir da obra de Maquiavel, verificaremos que uma multiplicidade de perspectivas continua em expansão em ordem inversamente proporcional a um inexistente consenso sobre o autor. Pelo prisma da reflexão crítica amparada por evidências textuais, Maquiavel é ora um patriota, ora um defensor da razão do estado, ora um romântico idealizador da Roma de Tito Lívio, ora um cínico, ora um republicano. A esse respeito, Maria J. Falco observa:

\begin{abstract}
Praticamente cada linha, cada pingo e cada título de cada carta, peça, poema e ensaio, bem como cada livro, história e "oração" que ele escreveu sofreu escrutínio minucioso. Nenhum outro autor submetido a escrutínio semelhante hoje poderia esperar sobreviver à quantidade de acusações, denúncias e elogios indo de protofascista a protoliberal - à qual Maquiavel tem sido assujeitado. ${ }^{3}$ (FALCO, 2004, p. 1-2)
\end{abstract}

A despeito das dificuldades de abordagem resultantes das ambiguidades e contradições de seus textos, é indiscutível que Maquiavel tem, ainda hoje, muito a nos dizer sobre as cruas realidades do poder, exercendo, portanto, grande impacto no discurso político moderno.

\title{
2 CONTEXTO HISTÓRICO
}

Maquiavel nasceu em 1469 em Florença, durante um período de transição política no qual a cidade-estado republicana com a constituição mais democrática do norte da Itália renascentista foi gradualmente dando lugar ao despotismo. O que faz de Florença um caso único entre outros regimes autoritários que se formaram na mesma época na península itálica é que, no período de transição que antecede os últimos quinze anos de vida de Maquiavel, a aparência das instituções que tinham caracterizado a república é mantida. Afinal, é através de expedientes menos visíveis, como o tráfico de influência, possbilitado pelo poder econômico de uma família de banqueiros que pôde lançar-se à compra de votos, que os Médici vão, pouco a pouco, solapando a república. Florença, que tinha sido o centro do levante ideológico contra o feudalismo, viu-se explicitamente à mercê dos usurpadores a partir de

3 Esta, bem como todas as outras traduções de citações publicadas em outras línguas que não português, é minha: "Virtually every line, every 'jot and title' of every letter, play, poem, essay, as well as every book, history, and 'prayer' that he ever wrote, has suffered minuscule scrutiny. No other writer undergoing similar scrutiny could hope to survive the range of accusations, denunciations and praises - ranging from protofascist to protoliberal - to which Machiavelli has been subjected." 
1512, um ano antes de Maquiavel ser preso e condenado por ter supostamente conspirado contra os Médici, perdendo seu emprego de secretário e chanceler da república e sendo multado e exilado depois de sobreviver a torturas físicas.

A partir de 1513, quando passou a viver em Sant'Andrea in Percussina, numa propriedade rural de sua família ao sul de Florença, Maquiavel, que sonhava com a unificação da Itália, começou a escrever as obras que o tornariam um dos mais importantes teóricos sobre a política no mundo. Boa parte da força motriz dessa obra, que se desenvolvia depois que o autor chegava de uma jornada de trabalho pesado na lavoura, foi o diletantismo de se apropriar dos mestres da tradição; e a outra parte foi a esperança de reaver um emprego compatível com sua formação intelectual. Considerando-se um exfuncionário do estado e não de um regime em particular, Maquiavel escrevia com a convicção de que, mais cedo ou mais tarde, suas palavras influenciariam uma mudança positiva na sociedade.

\section{PREMISSA METODOLÓGICA DESTE ARTIGO}

Para abordarmos a literatura dramática de um autor tão controverso e sujeito infelizmente a leituras engessadas, como Maquiavel, é necessário, antes de tudo, suspendermos todas as camadas de significados de modo que possamos ir às coisas nelas mesmas - princípio fundamental da Fenomenologia. Assim sendo, principalmente o texto teatral dirige esta reflexão; por certo, com o apoio de textos teóricos, mas sem perder de vista o fato de que uma peça de teatro, ao contrário de um tratado, não exprime o logos, mas o mythos e que, portanto, é ainda mais aberta a interpretações do que um tratado. Afinal de contas, não nasce com a missão de explicitar uma tese, mas com o intuito de divertir ainda que com substância significativa para a compreensão do mundo como palco de tensão de forças da convivência humana.

\section{A MANDRÁGORA}

\section{1 $O$ enredo}

Tendo morado por quase dois terços de sua vida em Paris, Calímaco Guadagni, burguês italiano com de trinta e dois anos de idade durante a ação da peça, era ainda uma criança quando deixou a Itália em decorrência de uma invasão de sua cidade. Por ocasião de uma conversa entre cavalheiros na qual está em disputa onde haveria mais mulheres belas, na França ou na Itália, Calímaco 
argumenta que a vantagem é da França. Porém, ao saber da existência de Lucrécia, dama florentina de beleza e virtude extraordinárias, decide ir à Florença com o forte intuito de conhecê-la. Apaixonando-se por ela à primeira vista, passa a nutrir o irrefreável desejo de possui-la ainda que seja por uma noite apenas.

Ocorre que Lucrécia é casada com Messer Nícia Calfucci e que o casal, malgrado as tentativas de gerarem filhos, parece ser estéril, sendo que o marido afirma não ser o lado responsável pela questão, dada sua considerável libido. Se Messer Nícia está dizendo a verdade o texto não revela. Como se trata de um homem mais velho, entretanto, é possível que seja um argumento falacioso. Embora riquíssimo e bem formado, Messer Nícia é completamente desprovido de sagacidade. Desse fato aproveita-se Ligúrio, homem de poucos recursos financeiros mas com esperteza de sobra, propondo um plano: apresentar Calímaco como um médico com excelentes credenciais e reputação inconteste na cura de casos de infertilidade.

Detentor de uma retórica cultivada que inclui um repertório de citações memorizadas em latim, Calímaco impressiona Messer Nícia ainda que sua prescrição desperte temor: Lucrécia deverá beber uma poção à base de mandrágora, raiz com propriedades fertilizantes, segundo alega o pseudo doutor. Mas a poção tem como efeito colateral a morte. No entanto, há um antídoto para o efeito letal: após a poção ser ingerida, Lucrécia deverá ter relações sexais, dado que o parceiro dessa atividade absorverá a toxicidade do remédio, contraindo, exclusivamente para si, as consequências irreversivelmente degenerativas e sucumbindo dentro de um período de oito dias.

Visto que o preço para a solução apresentada pelo pseudo médico é alto demais para o próprio marido, Ligúrio sugere a Messer Nícia que tal homem seja qualquer um que possa ser levado à força à casa de Lucrécia. Obviamente, o plano de Ligúrio inclui disfarçar Calímaco de vagabundo de modo que a farsa produza os resultados esperados. Ainda que resistente no início, Messer Nícia acaba concordando com a proposta. Mais difícil, contudo, seria contar com a adesão de Lucrécia, mulher virtuosa, nesse projeto sinistro. O obstáculo é contornado por Ligúrio através do suborno de Frei Timóteo, que, pela arte da persuasão, com um discurso legitimado pela Santa Igreja Católica, deverá convencer Lucrécia a se deitar com outro homem. Também contribui com a persuasão de Lucrécia, a opinião de sua mãe, Sostrata.

O plano de Ligúrio funciona como um relógio. Aparentando ser um 
vagabundo, Calímaco é recolhido de madrugada e se encontra com Lucrécia. Depois de uma noite de sexo, resolve contar tudo a ela. Supreendentemente, a virtuosa dama chega à conclusão de que toda a trama que permite seu encontro com Calímaco é obra da providência divina. De agora em diante, por sua própria decisão, Lucrécia manterá um caso amoroso secreto com Calímaco. Assim, a peça tem um desfecho feliz para todos, sendo que Messer Nícia jamais desconfiará de estar sendo ludibriado.

\subsection{Da arte da nomeação na comédia}

\subsubsection{Do título}

O título da comédia refere-se à raiz antropomórfica de uma planta conhecida desde a Antiguidade, quando chegou a ser usada como anestésico em cirurgias. Já os medievais e os renascentistas estavam mais interessados em suas propriedades comprovadamente alucinógenas e supostamente afrodisíacas. $\mathrm{O}$ fato é que a mandrágora, apesar da toxicidade real que a tornou um tema folclórico em várias culturas, nunca foi, ao menos historicamente, objeto de especulação com respeito a propriedades fertilizantes, e Maquiavel deixa claro que se trata de uma formulação quimérica cujo único intuito é o de enganar Messer Nícia. Cumpre notar, no entanto, que tais propriedades, no universo ficcional da comédia maquiaveliana, tornam-se indissociáveis de uma alegoria mais sutil: ao contrário de evidenciar-se como uma metáfora das raízes da corrupção da sociedade, a mandrágora parece funcionar como uma alegoria - a materialização do remédio psíquico necessário à restauração do senso de comunidade. Conforme observa Ronald L. Martinez,

[d]e fato, embora a lenda da mandrágora seja falsa na ficção da peça, o discurso farmacológico sugere como, no mundo real da história, a peça pode funcionar como um emético violento, um pharmacos, desenvolvido para diagnosticar e curar a enferma organização política florentina. As repúblicas, escreve Maquiavel em Discursos [sobre a primeira década de Tito Lívio] 3.1, devem ser restituídas periodicamente às suas origens, mesmo através de violência, ainda mais quando estiverem enfermas. ${ }^{4}$ (MARTINEZ, 2010, p. 216)

Visto que o nome do texto que nasce com o propósito de se tornar um

"Indeed, although in the fiction of the play the mandrake-lore is bogus, the pharmacological discourse suggests how in the real world of history the play might function as a violent emetic, a pharmacos, designed to diagnose and treat the diseased Florentine polity. Republics, Machiavelli writes in Discourses 3.1, must periodically be brought back to their origins, even through violence, the more so when diseased." 
evento teatral, ou seja, um rito com o potencial de visual, auditiva e emocionalmente envolver o público numa catarse coletiva cujo horizonte de expectativa parece ser o expurgo de uma ordem deficiente, ou doente mesmo, a fim de suscitar uma busca da cura, torna-se necessário, então, responder em que medida a mandrágora pode ser interpretada como um remédio - o que faremos mais adiante. Passemos, antes, aos nomes de personagens.

\subsubsection{Dos principais personagens}

No que tange a papéis, os co-protagonistas da comédia são Calímaco e Lucrécia, por serem os dois personagens que definitivamente influenciam a ação. Quanto à função, ambos são também herói e heroína, pois à Lucrécia, dada sua agência determinante no desfecho da trama, não se poderia atribuir a função de mocinha - à espera de um herói que a libertasse de Messer Nícia do confinamento numa torre.

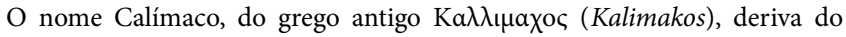

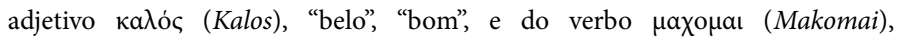
"combater". Portanto, Calímaco quer dizer "belo combatente" ou "bom combatente", significado que remete à virilidade e à beleza. Com efeito, Messer Nícia narra que, depois da "captura" de Calímaco, submete seu corpo, inclusive a genitália, a escrutínio a fim de verificar se o homem é realmente saudável. Com indisfarçável admiração, beirando o homoerotismo, o marido de Lucrécia, conclui um parecer favorável àquele que está destinado a prover a semente substitutiva que há de salvaguardar sua estirpe. Essa beleza e essa virilidade são representativas da virtus (virtude) romana, vocábulo derivado de vir, homem, implicando aquilo que é próprio do homem, na medida em que traduzem virilidade, força e potência. Calímaco, embora tenha determinação suficientemente apaixonada e vigorosa para a obtenção de seus propósitos, carece de uma inteligência que o guie no percurso rumo ao triunfo. Sem desprezar a base latina do conceito, Maquiavel o redefine na palavra italiana "virtù", acentuando a honra. Ainda vale ressaltar sobre Calímaco que seu sobrenome "Guadagni" significa "ganhos".

Para que a trajetória do virtuoso Calímaco possa dirigir-se aos ganhos, é necessária a articulação com um personagem secundário, com função de auxiliar de herói, Ligúrio. O nome "Ligúrio" deriva do verbo ligurire, que significa lamber e invejar ou desejar o que se lambe. Ligúrio, carrega, portanto, a pecha de um adulador, o qual precisa ser convidado a refeições para sobreviver. Diante de tal precariedade financeira, ua vontade de ascender é 
enorme. Além disso, não obstante a linhagem pobre e subalterna, que não lhe permite ter explorado outras cidades, ao contrário de Calímaco e Messer Nícia, Ligúrio é dotado de uma agudeza de espírito sem par na galeria de personagens da peça. Ligúrio não só traduz em estratégias sofisticadas o objetivo de Calímaco mas também o aconselha a revelar toda a farça à Lucrécia, ação que define a continuidade de um encontro que poderia reduzir-se a uma noite de capricho.

Embora a etimologia do nome "Lucrécia" seja mais controversa do que as dos outros personagens, muito provavelmente, atribui-se à origem do nome latino "Lucretia" ao substantivo lucrum, lucro, que nos leva ao campo semântico de riqueza e de sucesso. Maquiavel se inspirou em uma Lucrécia histórica e em outra mítica. A histórica era contemporânea de Maquiavel, irmã de César Bórgia e filha do Papa Alexandre VI. Famosa pela promiscuidade e por assassinatos, não pode ser descartada como referência que remete à complexidade da situação da comédia. A Lucrécia mítica é a descrita por um dos autores de cabeceira de Maquiavel, Tito Lívio. Há essencialmente também, no uso desse nome, uma reconfiguração do mito romano de Lucrécia, a bela e virtuosa esposa do nobre Lucius Tarquinius Collatinus, que é estuprada por Sextus Tarquinius, filho do tirânico rei de Roma. A Lucrécia romana exige do pai e do marido vingança pela ação sexual sem seu consentimento e depois comete suicídio com uma punhalada. Esse evento leva a uma rebelião popular que destrona os Tarquinius e funda a república romana. O nome "Lucrécia" é, portanto, um indício de como a micropolítica da privacidade de meia dúzia de indivíduos florentinos pode ser lida como a macropolítica da pólis. Se a Lucrécia do mito romano é co-responsável pela fundação da república, a Lucrécia renascimental é co-responsável pela instauração de um novo modus operandi e de um novo modus vivendi que podem perfeitamente servir de modelos para a restauração de uma comunidade baseada em liberdade pragmática ao invés de em leis arbitrárias e hábitos decrépitos, sedimentados pelas convenções sociais pelo Estado e pela Igreja.

Frei Timóteo, cujo nome deriva da combinação da palavra timor (temor) e da palavra palavra grega $\theta \varepsilon$ ć (Theo), "Deus", significando temor a Deus, é uma óbvia e ferina carnavalização do poder religioso. O objetivo principal de Frei Timóteo, além da própria sobrevivência, é a continuidade da Igreja Católica. Por isso, ainda que confrontado com a própria consciência, ele vai adiante na missão que lhe é confiada de persuadir Lucrécia a colaborar com o plano da poção de mandrágora apesar do terrível efeito colateral da infecção. O temor a 
Deus aqui, então, é hipócrita. Embora seja retratado com essas tintas satíricas, Frei Timóteo também desempenha função decisiva de auxiliar do herói na resolução da trama, resgatando seu papel de mentor espiritual ao burlar os códigos do patriarcado.

Representante-mor do patriarcado senil, o antagonista Messer Nícia recebe por nome uma antífrase. "Messer" é um título dado a um homem considerado uma autoridade, um senhor respeitável e certamente endinheirado. "Nícia" deriva da palavra grega Níkn (Nikê), "Vitória", a deusa da vitória. Obviamente, um perdedor bem nascido, que tem educação formal mas está longe de ter uma visão aguda das coisas, que tem poder mas não sabe para quê nem como usá-lo, Messer Nícia contrasta não somente com Calímaco mas também com Ligúrio, na medida em que esse representa o triunfo da racionalidade e aquele, o fiasco da irracionalidade.

\subsection{Da irracionalidade à racionalidade, ou da ilusão à realidade, ou da estagnação à restauração, ou ainda da esterelidade à fertilidade}

Retomemos a pergunta deixada em suspenso acima. Em que medida $A$ Mandrágora pode ser interpretada como um remédio, um pharmacos, um emético que promove o expurgo daquilo que envenena a sociedade?

Em primeiro lugar, é necessário afirmar que é razoavelmente compreensível que a obra de Maquiavel suscite o mal-entendido que chapa sua recepção hoje me dia. Afinal, abordando a corrupção dos cidadãos florentinos como um espelho da corrupção do mundo, a peça pode parecer incluir todos os personagens num mesmo espetáculo de degradação moral na escuridão de uma noite em que todos os gatos são pardos. Porém, há que se creditar os contrastes de caracterização como diversidades de visões de mundo e de possibilidades de ações no mundo, algumas construtivas, outras destrutivas.

Quando, por exemplo, Ligúrio descreve Lucrécia como uma "mulher bela, sábia, cultivada e apta a governar um reino" (I-3), devemos lhe dar crédito. Lucrécia reluta em participar do que considera um pacto maldito até onde é possível uma mulher se rebelar num mundo regido por homens. Mesmo depois de ceder à pressão argumentativa de Sostrata e de Frei Timóteo, ela hesita veementemente, não porque esteja convencida, ao contrário de seu marido, de que o homem que se deitar com ela após a ingesta da poção morrerá, mas 
porque está convencida de que o risco existe. Nesse horizonte, sem que Maquiavel explique o porquê do procedimento, o discurso de Frei Timóteo sofre uma modulação com respeito àquilo que é dito a Messer Nícia. Se nos detivermos na argumentação de Frei Timóteo, que afirma ter estudado a questão por mais de duas horas, veremos que sua ação não tem como força motriz somente o oportunismo:

No que diz respeito à consciência, a senhora deve confiar na seguinte regra genérica: que, quando há um bem certo e um bem incerto, não se deve jamais deixar esse bem pelo medo desse mal. Aqui, temos um bem certo, que é a senhora engravidar, adquirir uma alma para o Senhor Deus; o mal incerto é que aquele que se deitará com a senhora, depois da poção, morra; porém, há também aqueles que não morrem. Porque a coisa é dúbia, entretanto, o bom que é Messer Nícia não corra esse perigo. Quanto ao ato, que seja pecado, isso é uma fábula, porque a vontade é a que peca; não o corpo; e a razão do pecado é desagradar ao marido, e a senhora o agrada; ter prazer, e a senhora tem desprazer. Além disso, deve-se levar em consideração o fim em todas as coisas; seu fim é ocupar uma cadeira no paraíso, contentar seu marido. Diz a Bíblia que as filhas de Lot, achando que tinham ficado sós no mundo, copularam com o pai; e, porque a intenção delas foi boa, não pecaram. ${ }^{6}$ (III-11)

A primeira sentença da fala de Frei Timóteo pode soar como jogo de retórica. Mas a segunda modula a informação que o público tem até esse ponto. A argumentação que flexibiliza a determinação moral de Lucrécia é a possibilidade de que o homem-cobaia que se deitará com ela não venha a morrer. A incerteza do resultado da empreitada tem um peso exclusivo na decisão de Lucrécia. Seguindo a argumentação classista e parcial concernente a poupar Messer Nícia de um risco que pode ser transferido a outrém, Frei Timóteo retorna ao bem certo - note-se que, na ficção da peça, é uma convenção a ser aceita que o ato sexual entre Lucrécia e tal homem resultará em fertilização.

6 "Voi avete quanto a la coscienzia, a pigliare questa generalità, che, dove è un bene certo ed un male incerto, non si debbe mai lasciare quel bene per paura di quel male. Qui è un bene certo, che voi ingraviderete, acquisterete un'anima a messer Domenedio; el male incerto è che colui che iacerà, dopo la pozione, con voi, si muoia, ma e' si trova anche quelli che non muoiono. Ma perché la cosa è dubbia, però è bene che messer Nicia non corra quel pericolo. Quanto allo atto, che sia peccato, questo è una favola, perché la volontà è quella che pecca; non el corpo; e la cagione del peccato è dispiacere al marito, e voi li compiacete; pigliarne piacere, e voi ne avete dispiacere. Oltra di questo, el fine si ha a riguardare in tutte le cose; el fine vostro si è riempire una sedia in paradiso, contentare il marito vostro. Dice la Bibia che le figliole di Lotto, credendosi essere sole nel mondo, usorono con el padre; e, perché la loro intenzione fu buona, non peccorono". 
A argumentação que absolve o pecado do corpo se não houver adesão da alma é extraída ispis literis da versão da Lucrécia mítica retratada em Desde a Fundação da Cidade, de Tito Lívio. Que a Lucrécia renascentista siga as instruções à risca, bloqueando, pelo menos parcialmente, seu prazer, como nos é narrado por Calímaco, é uma prova de que se esforça ao máximo para manter-se virtuosa do ponto de vista das convenções, que ela só questionará depois que o plano lhe for revelado. Que Maquiavel tenha conscientemente convertido o mito da Lucrécia romana numa reconfiguração em que há, ainda que a contragosto, o consentimento da parceira no ato sexual, além da reviravolta cômica de salvaguardar um devir antes impensável, evidencia como Maquiavel retratou com bons olhos a ação de Lucrécia.

Por fim, Frei Timóteo lança um argumento insofismável que parece comprovar que ele tenha dedicado algumas horas ao estudo do caso: o episódio das filhas de Lot, que copulam com o pai depois de embriagá-lo com vinho. A Bíblia simplesmente narra a história sem fazer qualquer julgamento, o que implica um acolhimento neutro de uma situação tabu. A escolha dessa história bíblica como argumento conclusivo de Frei Timóteo denota multidimensionalidade na caracterização de um personagem que representa a hipocrisia exponencial.

Ao que parece, Maquiavel expõe uma razão fundamentada na prática que pode e deve transgredir as regras em nome da revitalização, que emerge, na peça, a partir do desejo sexual de Calímaco sobretudo. Embora faltem a Calímaco ideias engenhosas e firmeza no conseguimento de seus objetivos, quando Siro lhe adverte a respeito do cuidado que deve ter com Ligúrio, um oportunista, é o próprio Calímaco que, num rompante pragmático, lhe responde: " $[\mathrm{Q}]$ uando alguma coisa é conveniente a alguém, se pode botar fé que, quando lhe comunicarmos, esse alguém nos servirá com fé. Eu lhe prometi, quando puder, lhe fazer uma doação de uma boa soma de dinheiro" (I-1). Ao apostar todas as suas fichas na orientação de Ligúrio, Calímaco se engaja na dinâmica de um confronto pessoal com a coragem, atributo essencial para o favorecimento da deusa Fortuna. No momento histórico de gênese de A Mandrágola, instaura-se, no pensamento ocidental, uma perspectiva inovadora em relação às possibilidades das transações humanas. Conforme afirma Maria J. Falco,

[a] concepção de fortuna como receptiva ao esforço humano, a reaparição da

7 " $[\mathrm{Q}]$ uando una cosa fa per uno, si ha a credere, quando tu gliene communiche, che ti serva con fede. Io gli ho promesso, quando e' riesca, donargli buona somma di danari”. 
virtù simbolizando esse esforço, e a interpretação específica desse símbolo em termos de virilidade são recorrentes no Renascimento. Mas é Maquiavel quem apresenta a relação da ação humana em termos de conquista sexual - menos violenta do que o estupro porém mais enérgica do que a sedução. ${ }^{8}$ (FALCO, 1999, p. 57)

No polo oposto à disposição sexual de Calímaco, pontenciada pela expectativa do estratagema arrojado de Ligúrio, nos deparamos, não com a imobilidade de Messer Nícia, porque ele se agita, mas com a ineficácia de sua tagarelice e de seu afã. Quando Ligúrio informa Calímaco sobre a resistência que Messer Nícia tem com respeito ao conselho dos médicos antes consultados, ou seja, o de levar Lucrécia às termas, Ligúrio relata os obstáculos postos por uma personalidade que, tendo já viajado por grande parte da Toscana, é hoje um sedentário para quem deslocamentos espaciais para além dos limites de Florença soam como suplícios. Essa má vontade de Messer Nícia revela um homem nem um pouco afeito ao ímpeto. A oposição das caracterizações dos personagens do marido que está a um passo de se tornar o arquétipo do cornudo e do audacioso candidato a amante é radicalizada: Messer Nícia, homem "de pouco juízo e de ânimo menor ainda" (I-3). está mental e fisicamente embotado a ponto de ter bloqueado qualquer conexão com a oportunidade. Além disso, seu perfil de homem de inação é complementado por sua percepção limitada do divino: "[E]u creio que seja bom fazer as coisas com temor a Deus, e não atabalhoadamente" (V-4). Como o medo dita a relação do velho Nícia com as oportunidades, com a vida, a deusa Fortuna, de acordo com Maquiavel, nem mesmo se apercebe de sua existência, quanto mais de seus desejos anemicamente obsessivos. Em O Príncipe, Maquiavel afirma julgar que:

seja melhor ser impetuoso do que respeitoso, porque a fortuna é mulher, e é necessário, se for a intenção dominá-la, bater nela e sacudi-la. Aí veremos que se deixa vencer por esses ao invés de por aqueles que procedem friamente. E ainda, por ser mulher, é amiga dos jovens, porque são menos respeitosos, mais ferozes e com mais audácia a comandam. ${ }^{10}$ (MACHIAVELLI, 1964, 365)

"The conception of fortune as responsive to human effort, the revival of virtù as symbolizing that effort, and the specific interpretation of that symbol in terms of virility were widespread in Renaissance. But it is Machiavelli who presents man's relationship to the outcomes of human action in terms of sexual conquest - less violent than rape but more forceful than seduction." "di poca prudenzia, di meno animo".

10 "sia meglio essere impetuoso che rispettivo, perchè la fortuna è donna, ed è necessario, volendola tener sotto, batterla ed urtarla. E si vede che si lascia vincere da questi che da quelli che freddamente procedono. E però sempre, come donna, è amica de’ giovani, perchè sono meno rispettivi, più feroci 
Do ponto de vista político, Messer Nícia é incapaz de resgatar o senso de comunidade perdido. Portanto, na estrutura da pólis, ele é estéril, do mesmo modo como parace sê-lo biologicamente. Os contrastes entre Messer Nícia e seu rival, Calímaco, e Lucrécia dizem respeito a uma condição de prática social que é, do ponto de vista de Maquiavel, sine qua non, para o bem estar da comunidade: a disposição à criatividade. A criatividade maquiaveliana deve ser compreendida como a potência que move, a contento, tanto a coisa privada quanto a coisa pública.

Tal como emerge em A Mandrágora, o raciocínio de Maquiavel implica que a realidade política, como, de resto, todos os fenômenos sociais, estão sujeitos a duas forças: a agência humana e a contingência, que, metaforizada segundo a mitologia romana, assume a forma, como já vimos acima, da deusa Fortuna, em seu principal tratado político. O pensamento dominante no Renascimento era certamente moldado pela visão cristã, que atribui todo o peso da realidade à agência humana, ou seja, ao livre arbítrio. Há cerca de um milênio, essa questão tinha sido confrontada por Santo Agostinho em seu livro A Cidade de Deus, uma espécie de reescritura de A República, de Platão, no qual o doutor em Teologia estabelece princípios que afirmam o poder da Igreja Católica.

[A] fortuna - aquilo a que chamamos de boa fortuna - acontece aos homens, tanto aos bons quanto aos ruins, sem que pesem quaisquer de seus méritos; advém fortuitamente, daí seu nome Fortuna. Como ela pode ser boa se advém, sem descriminação, aos bons e aos maus? ${ }^{11}$ (SANTO AGOSTINHO, 2008, 4.18.21-5)

Segundo Santo Agostinho, a deusa Fortuna não tem poder sobre o mundo por conta de tratamento indiscriminado do bem e do mal. O problema do raciocínio de Santo Agostinho, do ponto de vista maquiaveliano é que não é tão óbvia a distinção entre bem e mal, pois o bem pode atingir um ponto de veemência no qual se transforme em mal, e vice versa. Maquiavel deixa claro que a contigência e o livre arbítrio são forças de intensidades equivalentes. Menosprezar a oportunidade, com suas configurações excepcionalmente anticonvencionais às vezes, corresponde a anular o vigor do livre arbítrio. Por isso, o desafio que Maquiavel lança contra a Igreja Católica não se encerra apenas na caracterização de Frei Timóteo, mas também abarca também, e

e con più audacia la comandano."

11 "[F]ortune - what we call good fortune - happens to men, to good and bad alike, without any weighing of their merits; it comes fortuitously; hence the name Fortune. How can she be good is she comes, without discrimination, to good and bad?" 
importantemente, a reviravolta cômica resultante da ação de Lucrécia, que desafiando a moralidade vigente, reformula sua visão de mundo e encontra um caminho inaudito para a sua existência:

Visto que a tua astúcia, a estupidez do meu marido, a ingenuidade da minha mãe e a malvadez do meu confessor me conduziram a fazer o que jamais por mim mesma teria feito, quero crer que venha de uma disposição celeste, que assim quis - e quem sou eu para recusar o que o Céu quer que eu aceite. Então, eu te tomo por senhor, patrono e guia: tu meu pai, tu meu defensor, e tu quero que sejas cada um dos meus bens; e o que o meu marido quis uma noite, quero que ele tenha sempre. ${ }^{12}(\mathrm{~V}-4)$

Não negligenciemos um desdobramento da trama que é essencial para a conclusão de Lucrécia. Depois de uma noite de sexo com Calímaco, certamente influenciada pelo conselho de Frei Timóteo, ela não interage com o parceiro desconhecido como poderia. Em outras palavras, o desempenho de Calímaco, por mais apaixonado que seja, por si só, não a impressiona. É a confissão de Calímaco, impregnada da narrativa de um percurso audacioso, além dos contornos imorais que envolvem o marido, o padre e a mãe, que a fazem despertar e tornar-se uma outra mulher, menos ingênua e mais realizada. $\mathrm{O}$ final feliz é uma proclamação de que a ventura carnal, humana em sua plenitude, supera a beatitude prometida pela Igreja, como atesta Calímaco:

Ao ouvir essas palavras, quase morri de tanta ventura. Não podia dar conta nem de uma parte ínfima do que teria desejado. O fato é que me acho o mais o homem mais feliz e contente que já existiu neste mundo; e, se essa felicidade não me faltasse, por morte ou por tempo, eu seria o mais beato que os beatos, mais santo que os santos. ${ }^{13}(\mathrm{~V}-4)$

Como, em A Mandrágora, o micropolítico representa o macropolítico, a ação de quebrar as regras de uma moralidade que embota a vida pode ser lida como a solução para dissolver a rigidez de instituições estéreis, dando lugar à

12 "Poiché lastuzia tua, la sciocchezza del mio marito, la semplicità di mia madre e la tristizia del mio confessoro mi hanno condutto a fare quello che mai per me medesima arei fatto, io voglio iudicare che venga da una celeste disposizione, che abbi voluto così, e non sono sufficiente a recusare quello che 'l Cielo vuole che io accetti. Però, io ti prendo per signore, patrone, guida: tu mio padre, tu mio defensore, e tu voglio che sia ogni mio bene; e quel che " 1 mio marito ha voluto una sera, voglio che egli abbia sempre."

13 "Io fui, udendo queste parole, per morirmi per la dolcezza. Non potetti rispondere alla minima parte di quello che io arei desiderato. Tanto che io mi trovo el più felice e contento uomo che fussi mai nel mondo; e, se questa felicità non mi mancasse, o per morte o per tempo, io sarei più beato che'i beati, più santo ch'i santi." 
constituição de novas formas de estruturação social nas quais a fertilidade seja a tônica. Ainda que representado por poucos personagens, o senso de comunidade da pólis é restaurado: a política volta a ser viva e a fazer sentido, e a humanidade se eleva da ignorância à vitória absoluta da razão.

\section{REFERÊNCIAS}

FALCO, Maria J. (Ed.) Introduction. Feminist Interpretations of Niccolò Machiavelli. University Park: The Pennsylvania State University, 2004. Pp. 1-38.

PITKIN, Hanna Fenichel. Meditations on Machiavelli. In FALCO, Maria J. (Ed.). Feminist Interpretations of Niccolò Machiavelli. University Park: The Pennsylvania State University, 2004. Pp. 49-92.

MACHIAVELLI, Niccolò. (1513: escrito; 1531: publicado) Il Principe. BURD, L. Arthur (Ed.). Oxford: Oxford University Press, 1891.

MACHIAVELLI, Niccolò. BONINO, Guido Davico (Org.). (1518) La Mandrágola. Torino: Einaudi, 1964.

MARTINEZ, Ronald L. Comedian, tragedian: Machiavelli and traditions of Renaissance theatre. In NAJEMY, John M. (Ed.). The Cambridge Companion to Machiavelli. Cambridge: Cambridge University Press, 2010. Pp. 206-222.

PITKIN, Hanna Fenichel. (1984) Fortune Is a Woman: Gender and Politics in the Thought of Niccolò Machiavelli. Chicago: The University Press of Chicago, 1999.

SAINT AUGUSTINE; BETTESON, Henry (Trad.). The City of God. London: Penguin Books, 1972. 


\title{
LA MANDRÁGORA, O LA FENOMENOLOGÍA DE LA OPORTUNIDAD EN MAQUIAVELO
}

Resumen: Este artículo pretende examinar la comedia La Mandrágora, de Maquiavelo, desde una lectura fenomenológica del texto. Este artículo es parte della reflexión feminista contemporánea de Machiavelo, desde que este punto de vista es perfectamente compatible con la agencia feminina e humana innegablemente representada en la pieza por la acción del personaje Lucrécia. Se argumenta que la oportunidad es dramatizada como una metáfora de la circunstancia de decisión, que es necessario afrontar con determinación a fin de hacer posible la restauración della pólis. También es una crítica della visión cristiana del mundo, bién estabelecida en el Renascimiento a través de la obra de Sant’Agostino; critica que consequentemente afirma la visión inherente en el pensamiento maquiavélico que la agencia humana, exactamente por estar limitada por la contingencia, tiene necesidad de romper la rigidez de las costumbres sociales en los momentos cruciales.

Palabras-clave: Agencia corporal. Fortuna. Política.

\section{THE MANDRAKE, OR THE PHENOMENOLOGY OF OPPORTUNITY IN MACHIAVELLI}

\begin{abstract}
This article aims to examine the comedy The Mandrake, by Machiavelli, from a phenomenological perspective of the playtext. The article draws upon a contemporary feminist critique of Machiavelli, since this vision is perfectly compatible with the feminine and human agency undeniably represented in the play by means of the action of the character Lucrecia. It argues that opportunity is dramatized as a metaphor of circumstance, which must be confronted with a determined sense of purpose in order to pave the way for the restoration of the polis. It also approaches Machiavelli's opposition to the Christian view of the world, well established in Renaissance by means of the diffusion of Saint Agostine's ouvre; this opposition consequently affirms the vision inherent in the Machiavellian thought that human agency, exactly for being limited by contingency, needs to transgress the rigidity of social habits in crucial moments.
\end{abstract}

Key-words: Bodily agency. Fortune. Politics. 
A Mandrágora, ou da fenomenologia da oportunidade em Maquiavel 